\title{
Filtro de dados baseado em rede neural artificial para remoção de ruídos da resposta de sensores SPR
}

\author{
Jackson Batista* Marcus Vinicius Silverio Costa* \\ Leiva Casemiro Oliveira* \\ * Programa de Pós-Graduação em Engenharia Elétrica \\ Universidade Federal Rural do Semi-Árido, Mossoró, RN. \\ (e-mails: jacksoncarlos31@gmail.com, [leiva.casemiro, \\ marcus.costa]@ufersa.edu.br).
}

\begin{abstract}
The SPR sensors are devices that use biological matter to detect physico-chemical iterations, so when immersed in poorly controlled environments, they develop a response with considerable noise level. Through the intelligent processing of data it aims to drain, in a general way, noises inherent to the process of analysis with SPR sensors. Based on the neural network methodology, an MLP RNA was designed that approached the experimental response of the sensor to the theoretical response, draining part of the noise from the experimental process.

Resumo: Os sensores SPR são dispositivos que utilizam matéria biológica para detecção de iterações físico-químicas, por esta razão quando imersos em ambientes pouco controlados, desenvolvem uma resposta com considerável nível de ruído. Através do processamento inteligente de dados objetiva-se drenar, de forma geral, ruídos inerentes ao processo de análise com sensores SPR. Com base na metodologia de redes neurais projetou-se uma RNA MLP que aproximou a resposta experimental do sensor a resposta teórica, drenando parte dos ruídos oriundos do processo experimental.
\end{abstract}

Keywords: Surface plasmon resonance; neural net; noise reduction; Smart Sensor.

Palavras-chaves: Ressonância de plasmons de superfície; rede neural; filtragem de ruídos; sensor inteligente.

\section{INTRODUÇÃO}

Os sensores baseados na ressonância de plasmons de superfície (SPR, Surface Plasmons Resonance) representam uma tecnologia formidável para o desenvolvimento de aplicações bioanalíticas tanto para a detecção de interações moleculares, quanto para a caracterização de meios e interfaces.

Em seu funcionamento, um sensor SPR converte variação de índice de refração (IR) em sinais óptico-elétricos Oliveira et al. (2015), e então, usa-os para monitorar eventos biológicos. Nas últimas décadas sensores SPR tornaramse uma tecnologia madura, onde diversas estruturas foram propostas e desenvolvidas para melhorar a qualidade desse tipo sensor. A remoção de partes móveis presentes no sensor Oliveira et al. (2013), o uso de fibras ópticas como guia de onda Sharma et al. (2007), novos protocolos para funcionalização de camadas biológicas Bieri et al. (1999) Sipova and Homola (2013) Ferreira et al. (2017) e novas configurações eletrônicas com uso de smartphones Liu et al. (2015) são exemplos de avanços que permitiram a obtenção de sensores de alta sensibilidade.

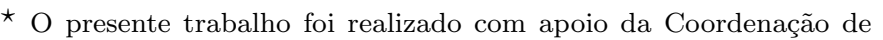
Aperfeiçoamento de Pessoal de Nível Superior - Brasil (CAPES) Código de Financiamento 001.
}

Os algoritmos para processamento da resposta SPR são outro fator impactante para o desenvolvimentos de sensores cada vez melhores. A escolha da estratégia para processamento do sinal de Sousa et al. (2015), a técnica usada para extração de características da curva SPR e supressão de deficiência apresentadas pelo uso de detectores ópticos (sensores de imagem) de baixa qualidade de Sousa et al. (2015), são situação tratadas por software e incorporados aos novos sensores SPR.

Os aspectos físicos e matemáticos que descrevem e modelam o funcionamento de um sensor SPR são amplamente descritos na literatura Oliveira et al. (2015) Filho (2017). Tipicamente, seu funcionamento consiste em iluminar uma estrutura multicamadas sob certas condições e capturar a luz refletida (sinal), fornecendo assim uma assinatura óptica para essa estrutura. O sinal captado passa por processos de filtragem e então utilizado para gerar de forma gráfica a ressonância, denominado de curva SPR. A Figura 1, apresenta os elementos constituintes de um sensor SPR, com destaque para os fatores que influenciam diretamente na sua resposta.

Dada a heterogeneidade da instrumentação de um sensor SPR, inúmeras são as fontes de ruído que podem afetar o desempenho e qualidade de sua resposta. Cada componente contribui de forma específica para excitação dos plasmons de superfície e por conseguinte são suscetíveis a 
a) $\begin{cases}\text { Célula de fluxo } & \text { Pelocidade } \\ \text { Propulsor } & \text { Vazão }\end{cases}$ Amostrador

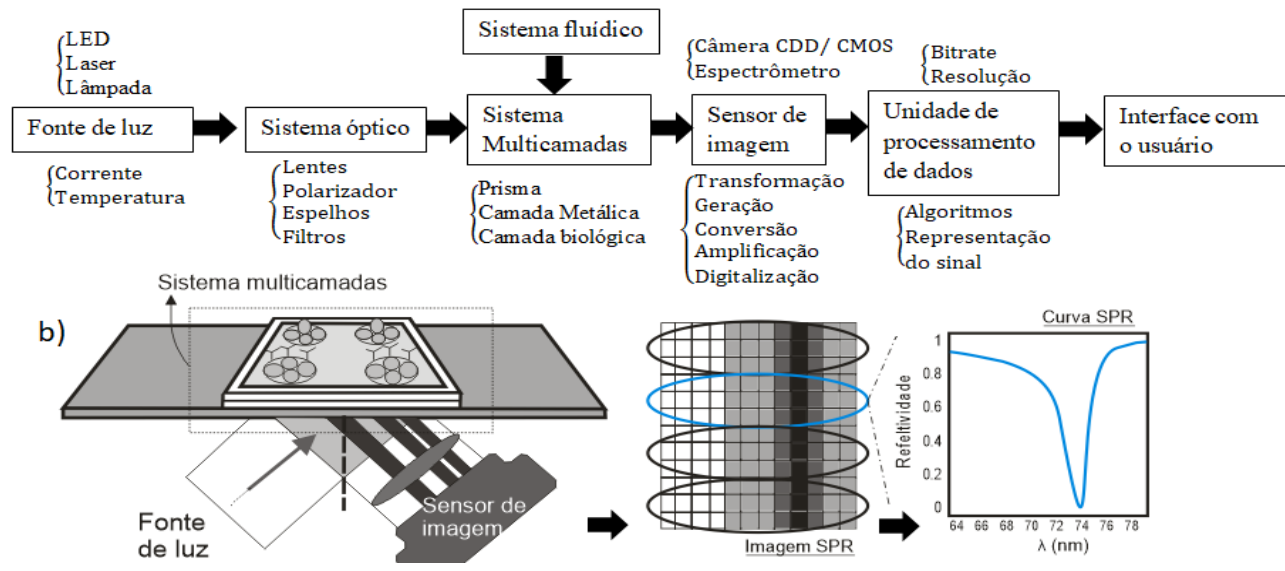

Figura 1. a) Diagrama de blocos de um sensor SPR com destaque para os elementos que compõem cada bloco e/ou fatores que influenciam na resposta do sensor. b) Esquema ilustrativos de um sensor SPR. A luz refletida é convertida na curva SPR e seu valor mínimo representa a posição de ressonância.

fontes de ruídos distintas. A fonte de luz afeta a posição de ressonância uma vez que a intensidade e o comprimento de onda incidente dependem de ajustes precisos de temperatura e corrente. Com isso, mais fótons podem atingir o sensor de imagem, influenciando o ruído shot e o ruído associado a corrente escura. A rugosidade do prisma dificulta a deposição de filme metálico com espessura correta, bem como a ligação de substâncias biológicas na superfície que também depende de ajustes no sistema fluídico, acarretando em curvas SPR menos acentuadas.

Tentativas de quantificar, modelar e compensar as distorções individuais causadas em cada componente, tornam-se tarefa árdua, com vista a introduzir ainda mais anomalias na resposta SPR Filho (2017). Compensar o ruído de um único componente específico resolve problemas pontuais, o que muitas vezes é insuficiente para obtenção de uma resposta SPR satisfatória.

Este trabalho tem por objetivo criar um filtro de dados baseado em rede neural artificial (RNA) para remoção de ruídos na resposta de sensores SPR. Com a RNA foi obtido um modelo unificado para a resposta ideal do sensor, e assim, compensar todos os ruídos presentes na instrumentação do sensor desenvolvido.

\section{FILTRO SPR BASEADO EM RNA}

As características de uma curva SPR podem atestar a qualidade do sensor. Em geral o contraste/profundidade, largura, assimetria, declividade, posição do valor mínimo, energia e fase são características observadas e monitoras em uma curva SPR. Uma curva SPR experimental traz consigo todo o conjunto de ruídos presentes no sensor SPR, que consequentemente, afetam o desempenho do mesmo. Desse modo, foi então criado uma rede neural capaz de compensar as curvas experimentais (ruidosas) a partir de curvas SPR teóricas (ideais) e assim melhorar a performance do sensor.

A seguir, são apresentadas as etapas metodológicas para criação do sensor SPR inteligente com filtro de dados baseado em RNA. Em síntese, curvas teóricas foram geradas para um sensor com a estrutura multicamadas contendo prisma de vidro BK7 e camada metálica de 50nm de ouro. Em seguida, são obtidas curvas experimentais com o sensor SPR desenvolvido com a mesma estrutura multicamadas. Por fim, projeta-se uma RNA que atua na resposta de saída, drenando resíduos e filtrando os dados experimentais para eliminar parte dos ruídos inerentes aos procedimentos experimentais.

\subsection{Curvas SPR Teóricas}

A interação luz-matéria computada por um sensor SPR pode ser obtida através da Análise de Fresnel (AF) Oliveira et al. (2015). A ressonância é então obtida variando as condições de acoplamento entre um feixe de luz e os plasmons de superfície. Dentre as formas para se obter tais condições, é possível desenvolver sensores SPR capazes de operar no chamado modo de interrogação espectral (WIM - Wavelength Interrogation Mode), em que o ângulo da luz incidente é fixado e uma luz com comprimento de onda variável (policromática) é empregada para obtenção da condição de ressonância Oliveira et al. (2015). No modo WIM a posição de ressonância, denominada de comprimento de onda de ressonância $\lambda_{R}$, é indicada pelo valor mínimo da curva SPR.

A AF foi realizada para variações de índice de refração da ordem de $5 \times 10^{-} 3$ RIU (Refractive Index Unit), equivalente à análise das substâncias águas deionizada e desgaseificada $\left(\mathrm{H}_{2} \mathrm{O}\right)$, soluções de PBS (Phosphate Buffered Saline), da proteína BSA (Albumina Sérica Bovina) diluída em água, a concentração de $0,1 \mathrm{mg} / \mathrm{ml}$ e de hipoclorito (Hipo.). A Figura 2 exibe as curvas teóricas para os analitos (substâncias) citados.

\subsection{Curvas Experimentais: set-up experimental}

Para obtenção das curvas experimentais foi utilizado um sensor SPR baseado no PPBIO (Prisma Polimérico para aplicação BIOlógicas) Moreira et al. (2009). Devido a sua geometria trapezoidal (ver Figura 3a), o PPBIO torna menos dispendiosa a instrumentação de um sensor SPR 


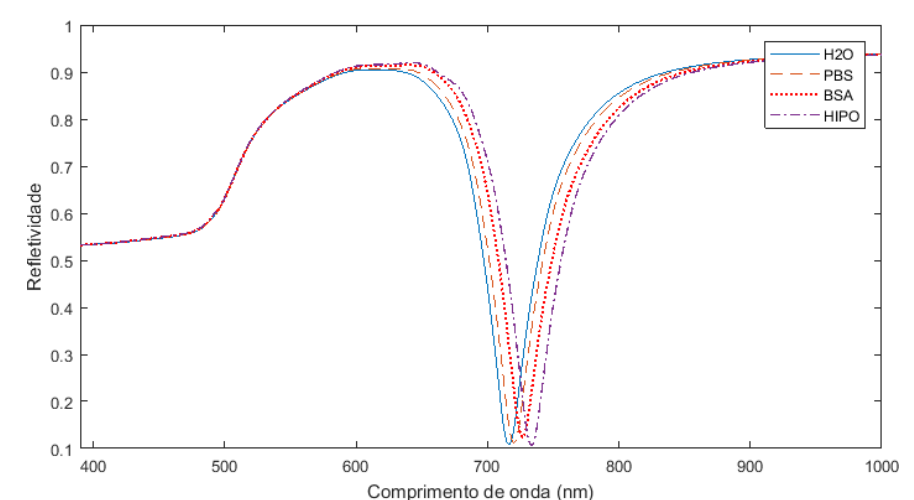

Figura 2. Cuvas SPR teóricas do sensor com prisma de $\mathrm{BK} 7 / \mathrm{Au}$ ( 50nm) para $\mathrm{H}_{2} \mathrm{O}$, PBS, BSA e Hipo.

por evitar partes móveis e/ou rotacionais. As paredes laterais inclinadas do PPBIO são especulares para facilitar a reflexão da luz incidente. Esse prisma possui uma fina camada metálica depositada na base superior, evitando o uso de óleo/gel para acoplamento da superfície metálica. Para mais detalhes sobre o sensor SPR baseado no PPBIO recomenda-se as referências Oliveira et al. (2013); Oliveira et al. (2016).

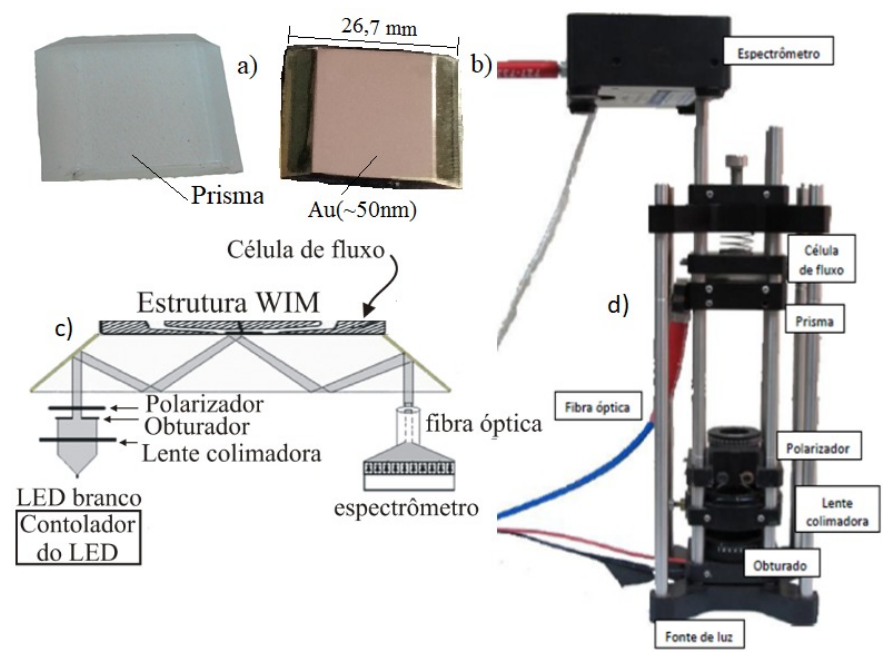

Figura 3. Fotografia do PPBIO a) antes e b) depois da deposição de 50nm de ouro. c) diagrama de blocos do sensor e d) fotografia do set-up experimental.

As curvas experimentais obtidas para as substâncias $\mathrm{H}_{2} \mathrm{O}$, PBS, BSA e Hipo., encontram-se na Figura 4.

\subsection{Projeto da RNA}

As características de uma curva SPR são mensuradas através de contraste/profundidade, largura, assimetria, declividade, posição do valor mínimo, energia e fase, possuindo alta dimensionalidade, todavia, pode-se utilizar a distribuição espectral, o índice de refração da substância e a refletividade da substância como representação geral das curvas SPR, cada curva é representada por 3000 pontos. Tem-se como entrada da RNA as curvas experimentais representadas pelos três parâmetros citados anteriormente. A saída do filtro é uma curva SPR filtrada nos moldes de uma curva SPR teórica.

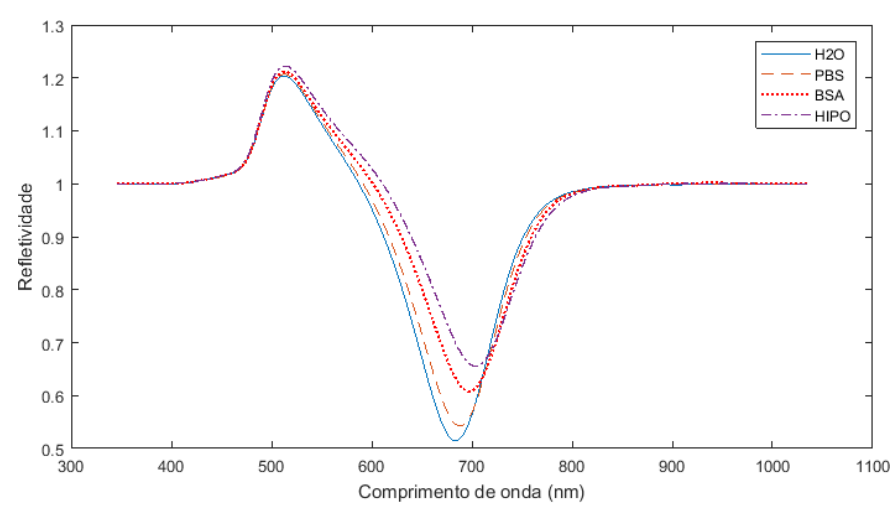

Figura 4. Curvas SPR experimentais para $\mathrm{H}_{2} \mathrm{O}, \mathrm{PBS}, \mathrm{BSA}$ e Hipo. obtidas com o sensor desenvolvido com prisma de $\mathrm{BK} 7 / \mathrm{Au}(50 \mathrm{~nm})$.

A rede deve ser alimentada adiante, pois o campo induzido dos neurônios devem ser influenciados apenas pela camada de entrada proveniente das curvas experimentais. Considerando a não linearidade das curvas SPR, adota-se como função de ativação dos neurônios as funções sigmoides, onde os neurônios são modelados com base na Equação (1). Além da motivação por ausência de linearidade, a função sigmoide leva em conta a fase refratária de neurônios reais, a qual delimita as regiões onde um sinal de excitação pode gerar ou não potencial de ação. (Haykin, 2008).

$$
y=\frac{1}{1+\exp (-u)},
$$

A quantidade de neurônios nas camadas escondidas foi escolhida com base na metodologia de Huang (2003). Mantendo uma taxa de aprendizagem constante e definindo como critério de parada o erro médio quadrático menor que 0.01 foram selecionadas nove RNAs que apresentaram valores de índice de correlação aceitáveis para o propósito desse trabalho. A Tabela 1, sumariza as combinações na quantidade de neurônios que apresentaram respostas satisfatórias.

Tabela 1. Diferentes combinações na quantidades de neurônios das camadas escondidas 1 e 2 e seus respectivos parâmetros estatísticos.

\begin{tabular}{ccccccc} 
RNA & L1 & L2 & EMQ & ICMV & ICMT & Épocas \\
\hline 1 & 8 & 4 & 0,0095 & 0,8916 & 0,6251 & 43 \\
2 & 8 & 9 & 0,0097 & 0,7008 & 0,4873 & 47 \\
3 & 9 & 11 & 0,0090 & 0,8708 & 0,5659 & 39 \\
4 & 9 & 13 & 0,0094 & 0,8136 & 0,4936 & 37 \\
5 & 10 & 6 & 0,0094 & 0,9350 & 0,7225 & 31 \\
6 & 12 & 7 & 0,0085 & 0,8542 & 0,6067 & 34 \\
7 & 12 & 8 & 0,0087 & 0,9056 & 0,6795 & 36 \\
8 & 13 & 8 & 0,0086 & 0,9595 & 0,7879 & 36 \\
9 & 13 & 13 & 0,0096 & 0,7470 & 0,5130 & 39 \\
\hline
\end{tabular}

Levando em consideração o ICMV (Índice de correlação do modelo validado), o ICMT (Índice de correlação do modelo testado) e o número de épocas, adota-se a RNA 8. o Número de épocas é inversamente proporcional a velocidade de convergência.

Considerando todos os aspectos mencionados anteriormente, o filtro consiste de uma RNA Multilayer Perceptron (MLP) que tem como parâmetros de entrada a distribuição 


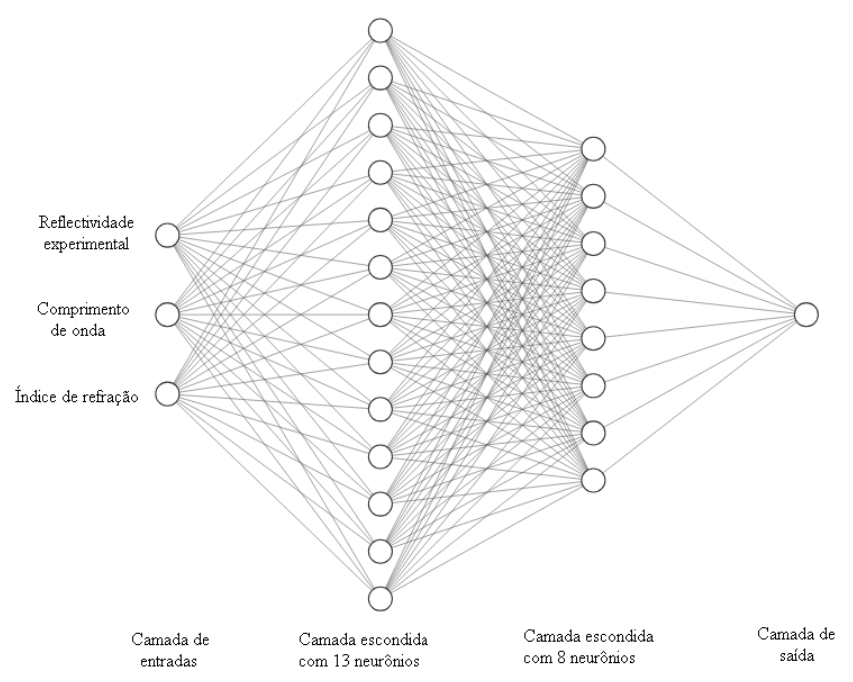

Figura 5. Arquitetura da rede neural embarcada no sensor SPR inteligente para atuar como filtro de dados SPR.

espectral da fonte de luz, o índice de refração e as refletividades das substâncias, a saída do filtro é uma curva aproximadamente igual a uma curva SPR teórica.

A arquitetura para a RNA MLP com duas camadas escondidas é apresentada na Figura 5. A rede possui alta conectividade, em que cada neurônio da camada anterior possui ligação com os neurônios da camada posterior, divergindo das redes convolucionais que analisam campos receptivos locais. Desse modo, consegue-se analisar o comportamento global da curva SPR.

Através da Figura 6 investiga-se a relação entre o coeficiente de aprendizagem $(\mathrm{N})$ e resposta do regime transitório, aumentando-se o coeficiente aumenta-se o percentual de overfit bem como a velocidade de convergência. Através da Tabela 2 observa-se que o ICMT e o o EMQ é maior próximo a região de $\mathrm{N}=0,75$. Escolhe-se $\mathrm{N}$ igual a 0,31 por apresentar baixo percentual de overfit e boa classificação estatística.
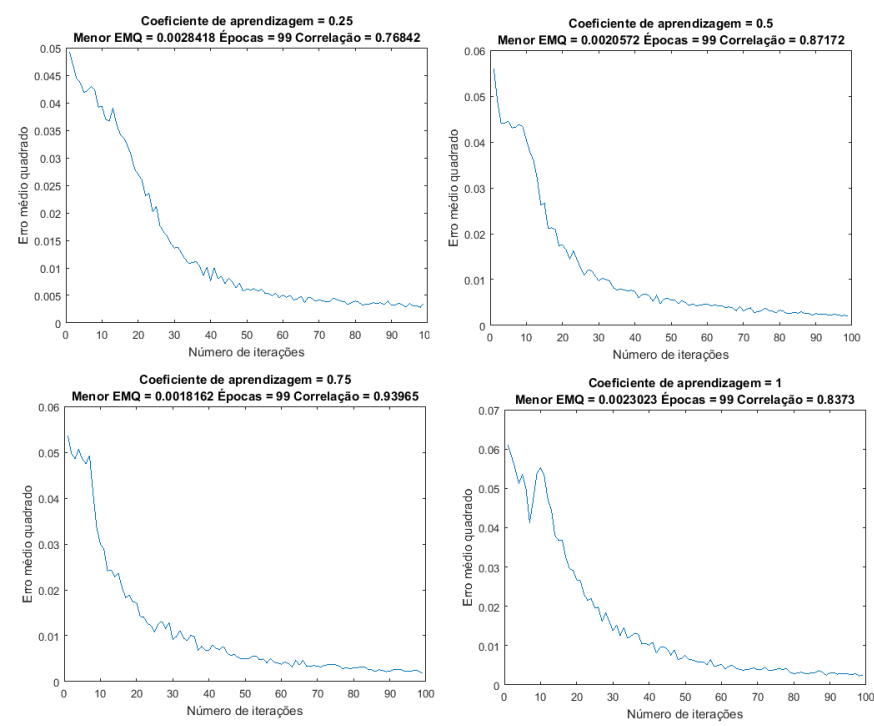

Figura 6. influência de N sobre regime transitório
Tabela 2. Influência de N sobre ICMT e EMQ.

\begin{tabular}{cccc}
$\mathrm{N}$ & EMQ & ICMT & Épocas \\
\hline 0.25 & 0,0028 & 0,7684 & 99 \\
0.5 & 0,0020 & 0,8717 & 99 \\
0.75 & 0,0018 & 0,9396 & 99 \\
1 & 0,0023 & 0,8373 & 99 \\
\hline
\end{tabular}

Treinamento, validação e teste

Para o treinamento foram utilizadas as curvas SPR da água, PBS e Hipoclorito. Adota-se o método de aprendizagem supervisionada via backpropagation. Com base no resíduo gerado entre a refletividade teórica desejada e refletividade teórica obtida na AF, calcula-se o gradiente local, e os novos pesos e bias necessários para correção do erro instantâneo são atualizados.

Na Figura 7 exibe-se a curva de aprendizagem de ensemble, demonstrando-se a taxa de convergência da RNA durante o treinamento. Observa-se estabilização na resposta permanente pelo critério do EMQ mínimo.

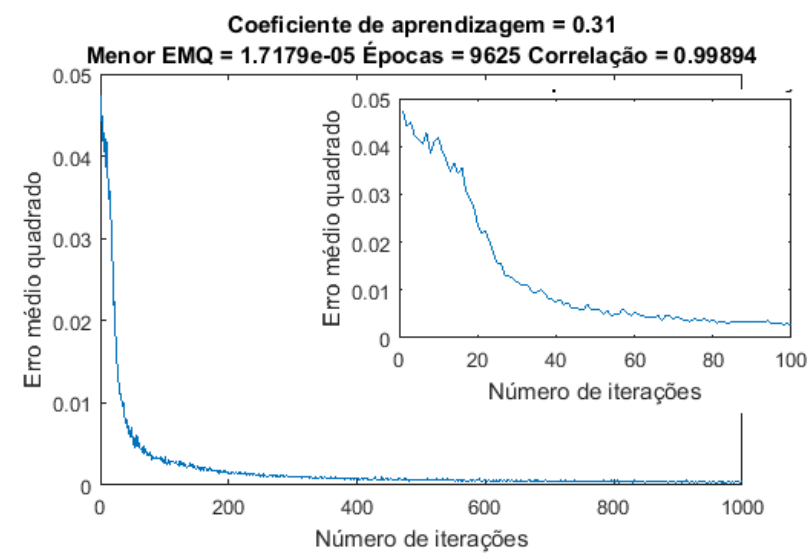

Figura 7. Curva de ensemble para a RNA 8 após 9625 épocas. Destaque para o regime transitório presente nas primeiras 100 épocas.

Após validar a aprendizagem da RNA com uma das curvas treinadas, realiza-se o teste com a curva não treinada (BSA). Na fase de teste, são computadas informações estatísticas sobre o erro médio quadrático (EMQ) e o índice de correlação entre a resposta da RNA e a resposta desejada.

Com os pesos e bias treinados, o filtro de dados baseado em RNA é embarcado no software do sensor, criando assim, um sensor SPR com resposta inteligente. Para o teste dinâmico do filtro, um protocolo experimental foi definido e as curvas SPR foram filtradas em temporeal. O monitoramento da posição de ressonância $\left(\lambda_{R}\right)$ é apresentado no gráfico denominado de sensorgrama.

\section{RESULTADOS E DISCUSSÕES}

\subsection{Teste estático}

Para o teste estático foi utilizado a curva SPR experimental para a solução de BSA. Na comparação entre as curvas teóricas e experimentais, nota-se que a curva experimental apresenta um valor de contraste menor do que a curva 
teórica. Isso deve, majoritariamente, ao fato de a camada metálica ter espessura menor do que a ideal Oliveira et al. (2015). A posição de ressonância difere em aproximadamente 40nm, devido a pequenas diferenças entre os valores para a propriedade óptica do metal usada na simulação e as obtidas após a deposição do metal. Além disso, a curva experimental apresenta uma proeminência em torno de 520 nm devido a rugosidade do prisma, levando a excitação dos plasmons radiativos Neff et al. (2018).

A comparação entre a curva teórica e a curva de saída gerada pela RNA, tendo como entrada a curva experimental é apresentada na Figura 8. O resultado da aplicação do filtro apresentou baixo valor de EMQ, indicando um alto valor de correlação de aproximadamente 0,99 , como mostra a Figura 9. Todos os ruídos que afetaram a forma da curva foram removidos.

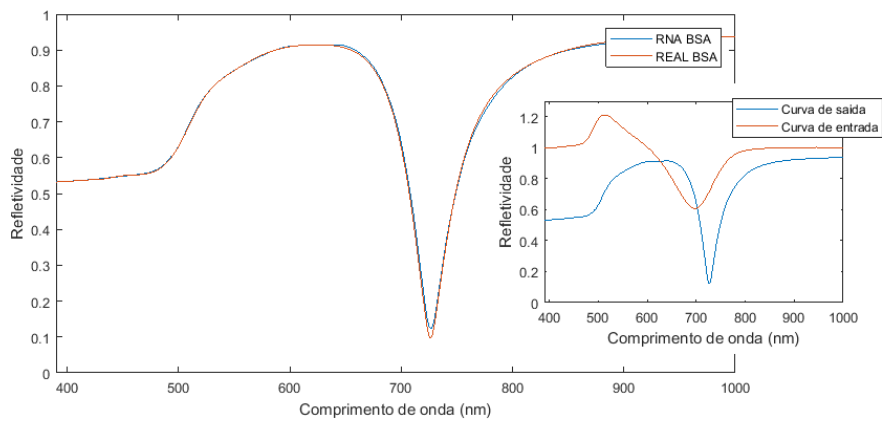

Figura 8. Comparação entre a curva teórica e a curva gerada pela RNA após aplicação do filtro. Resposta SPR para a solução de proteína BSA. Destaque para as diferenças entre as curvas teórica e experimental.

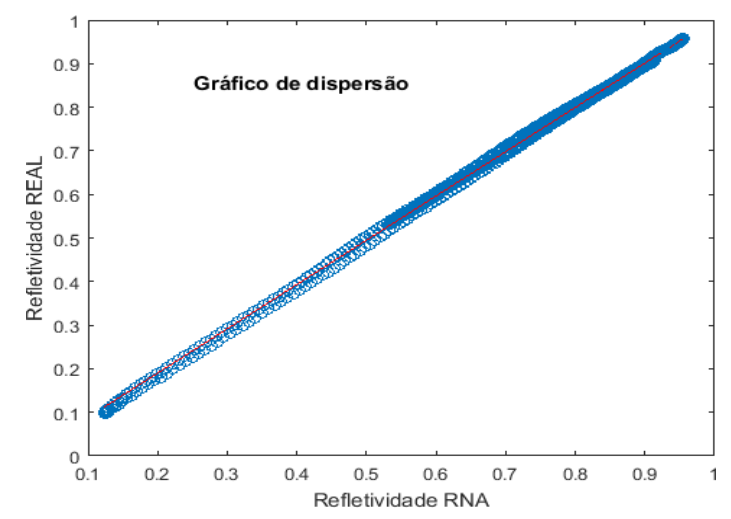

Figura 9. Gráfico de dispersão entre refletividade teórica e refletividade gerada pela RNA.

\subsection{Teste dinâmico}

Para verificar o funcionamento do sensor inteligente com o filtro RNA embarcado, definiu-se um protocolo experimental com os analitos já apresentados. O protocolo seguiu o ciclo experimental: $\mathrm{H}_{2} \mathrm{O} \rightarrow \mathrm{PBS} \rightarrow \mathrm{H}_{2} \mathrm{O} \rightarrow$ Hipoclorito $\rightarrow \mathrm{H}_{2} \mathrm{O} \rightarrow \mathrm{PBS} \rightarrow \mathrm{H}_{2} \mathrm{O} \rightarrow \mathrm{BSA} \rightarrow \mathrm{H}_{2} \mathrm{O} \rightarrow$ Hipoclorito $\rightarrow \mathrm{H}_{2} \mathrm{O}$.

Na Figura 10 demonstra-se a aplicação do filtro para o ciclo experimental. Ao todo 862 curvas foram geradas. O filtro teve seu comportamento atestado, removendo os ruídos intrínsecos ao sensor e não sendo afetado por cinéticas químicas oriundas das transições entre substâncias com diferentes índices de refração.

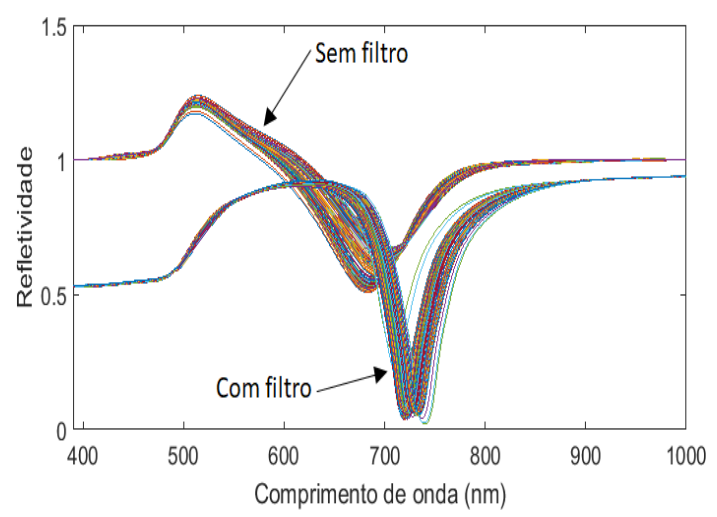

Figura 10. Curvas SPR experimentais obtidas com a execução do protocolo experimental. Sem o filtro as curvas apresentam mudanças de forma devido aos ruídos presentes no sensor. Após a aplicação do filtro, as curvas apresentam formas semelhantes aos resultados teóricos.

O desempenho do sensor inteligente embarcado com o filtro RNA proposto foi realizado. Para tanto, os sensorgramas da posição de ressonância $\lambda_{R}$ para as curvas SPR sem e com a aplicação, indicam que o filtro apresentou valores de $\Delta \lambda_{R}$ semelhantes, apresentando assim sensibilidade $S$ equiparável ao sensor sem o filtro, conforme Figura 11.

Vale destacar que após a aplicação do filtro, a curva SPR tem sua forma ajustada, o que melhora substancialmente o sensoriamento através das característica contraste/profundidade, largura, assimetria e energia da curva.

\section{CONCLUSÃO}

Um filtro para remoção de ruídos da resposta de sensores SPR foi apresentado. A partir da curva SPR gerada pelo sensor, o filtro remove os ruídos intrínsecos ao sensor corrigindo as características da curva SPR.

A RNA MLP generaliza a aplicação da metodologia desenvolvida, devido a capacidade de aprendizagem, o filtro pode se adaptar a outras formas de ruídos. Os resíduos contornados pelo filtro aparecem de modo geral no processo. Ruídos pontuais provenientes de erros específicos podem ser eliminados via métodos estatísticos.

Melhorias no critério de aprendizagem e na automação da arquitetura da rede - através de métodos como o filtro de Kalman, bem como a implementação de métodos estatísticos de correlação mais rigorosos que levam em conta a polarização dos dados são aspectos a serem investigados.

\section{AGRADECIMENTOS}

O presente trabalho foi realizado com apoio da Coordenação de Aperfeiçoamento de Pessoal de Nível Superior Brasil (CAPES) - Código de Financiamento 001.

\section{REFERÊNCIAS}

Bieri, C., Ernst, O., Heyse, S., Hofmann, K., and Vogel, H. (1999). Micropatterned immobilization of a g pro- 


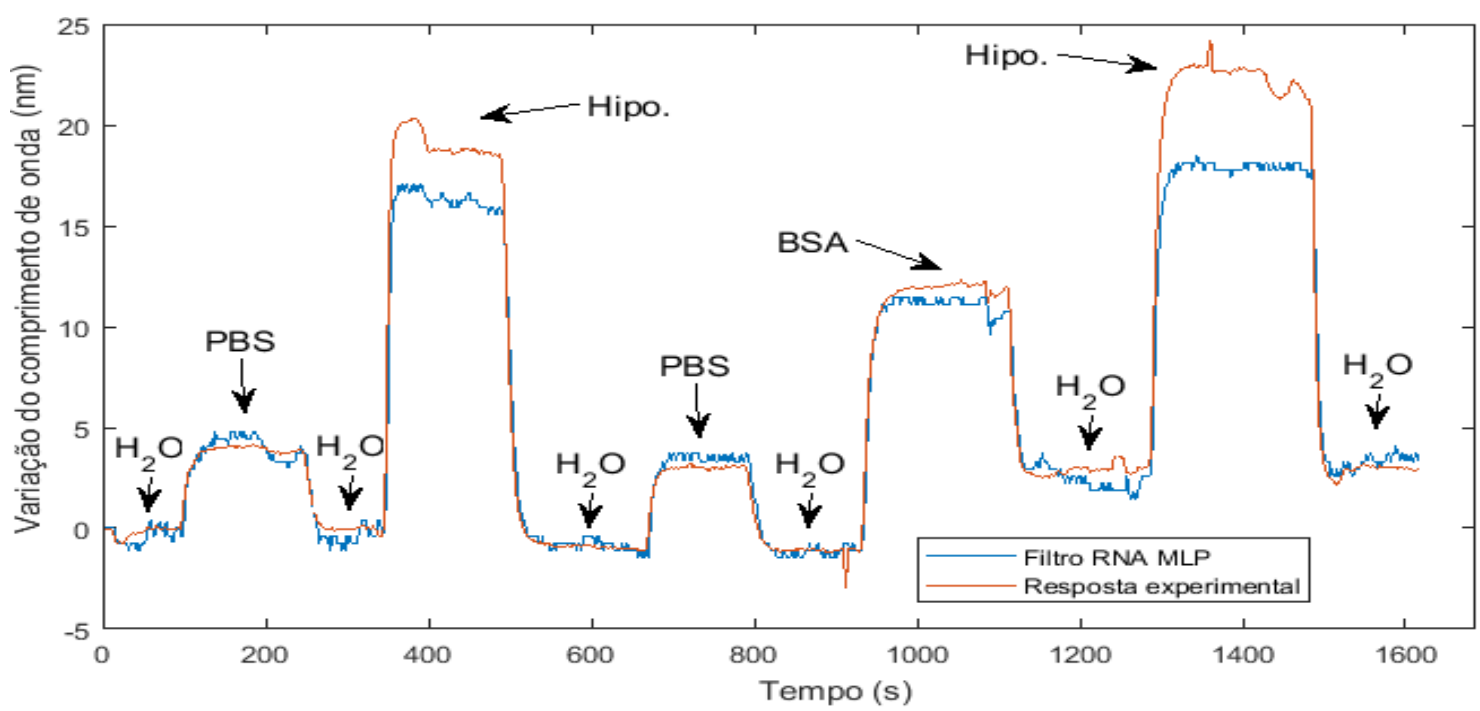

Figura 11. Sensorgrama experimental para os valores de $\lambda_{R}$ gerado sem (vermelho) e com (azul) a aplicação do filtro RNA. Valor mínimo detectado com o algoritmo do ajuste polinomial.

tein-coupled receptor and direct detection of $\mathrm{g}$ protein activation. Nat. Biotechnol, 17, 1105-1108.

de Sousa, T., Oliveira, L., Loureiro, F., Lima, A., and Neff, H. (2015). Evaluating the signal processing chain employed in surface plasmon resonance biosensing. I2MTC Proceedings, 1, 1606.

Ferreira, E., Oliveira, L., Goulart, L., and et. al.. (2017). Leishmania spp. detection using a surface plasmon resonance biosensor. Proceedings, 1, 53.

Filho, C. (2017). Contribuição ao Projeto de Sistemas Multianalíticos Baseados em Ressonância de Plasmons de Superfícies. Tese de doutorado, Universidade Federal de Campina Grande.

Haykin, S. (2008). Redes Neurais princípios e práticas. bookman, São Paulo.

Huang, G.B. (2003). Learning capability and storage capacity of two-hidden-layer feedforward networks. IEEE TRANSACTIONS ON NEURAL NETWORKS, 14, 274-281.

Liu, Y., Liu, Q., Chen, S., Cheng, F., Wang, H., and Peng, W. (2015). Surface plasmon resonance biosensor based on smart phone platforms. Sci. Rep., 5, 12864.

Moreira, C., Neto, A., Lima, A., Thirstrup, C., and Neff, H. (2009). Exchangeable low cost polymer biosensor chip for surface plasmon resonance spectroscopy. Procedia Chemistry, 1, 1479-1482.

Neff, H., Oliveira, L., Rodrigues, E., Thirstrup, C., and Lima, A. (2018). Enhanced directed radiative surface plasmon emission from periodically corrugated noble metal films. Plasmonics, 1, 1-8.

Oliveira, L., Lima, A., Thirstrup, C., and Neff, H. (2015). Surface plasmon resonance sensors - a materials guide to design and optimization.

Oliveira, L., Moreira, C., Lima, A., and Neff, H. (2016). A prism-based polymeric surface plasmon resonance biochip for angular and spectral modes. Procedia Engineering, 168, 1350 - 1353.

Oliveira, L., Morerira, C., Thirstrup, C., Melcher, E., Lima, A., and Neff, H. (2013). A surface plasmon resonance biochip that operates both in the angular and wavelength interrogation modes. IEEE TIM, 62(5),
$1223-1232$.

Sharma, A., Jha, R., and Gupta, B. (2007). Fiberoptic sensors based on surface plasmon resonance: A comprehensive review. IEEE Sensors J., 7, 1118-1129.

Sipova, H. and Homola, J. (2013). Surface plasmon resonance sensing of nucleic acids: a review. Analytica Chimica Acta, 773, 9-23. 